\title{
Construção de Objetos de Aprendizagem para a Educação Básica por Meio de um Curso Sobre o Scratch para Estudantes de Licenciaturas
}

Ana Paula de Andrade Janz Elias - UNINTER - anapjanz777@gmail.com

Marcelo Souza Motta - UTFPR-Curitiba - msmotta27@gmail.com

Marco Aurélio Kalinke - UTFPR-Curitiba - marcokalinke@yahoo.com.br

\section{RESUMO}

Apresentamos neste trabalho como ocorreu um curso de capacitação para utilização do Scratch, ofertado para estudantes de diferentes licenciaturas, matriculados em um centro universitário de Curitiba. Destacamos que o software Scratch é uma ferramenta de programação intuitiva, gratuita e acessível a todos os públicos. Os objetivos do curso eram capacitar os participantes na utilização do software, bem como apresentar as suas potencialidades no contexto educacional. A pesquisa apresenta características qualitativas e utilizou como instrumentos metodológicos o próprio software Scratch, a observação e os Objetos de Aprendizagem (OA) desenvolvidos pelos participantes. Os dados aqui apresentados mostram que é possível, por meio de um curso de extensão, levar estudantes de cursos de licenciatura a conhecer o Scratch e a desenvolver programações, de forma intuitiva.

Palavras-chave: Scratch; Formação de professores; Tecnologias Digitais; Objetos de Aprendizagem;

\section{Construction of Learning Objects for Basic Education Through a Scratch Course for Undergradua Students}

\begin{abstract}
We present in this work the training course on Scratch software utilization, offered to students of different degrees, enrolled in a university in Curitiba. We emphasize that Scratch software is an intuitive programming application, free and accessible to all. The objectives of the course were enable participants to use the software and present their potential in the educational context. The research presents qualitative nature and used as methodological instruments: the software Scratch, the observation and Learning Objects (LO) developed by the participants. The data presented here evidence that it is possible, throught an extension course, to take undergraduate students to know Scratch and to develop applications, in an intuitive way.
\end{abstract}

Keywords: Scratch; Teacher training; Digital Technologies; Learning Objects;

\section{Introdução}

O uso de ferramentas tecnológicas digitais no contexto de sala de aula tem sido alvo de investigação por parte de diferentes autores e educadores. Estudos sobre o uso de lousa digital, realizados por Derossi (2015) e Ribeiro (2015) e, o uso de smartphones nas salas de aula, desenvolvidos por Borba e Lacerda (2015) e Romanello (2016), fazem parte dessas pesquisas. Outro tipo de investigação acadêmica, a partir desta temática, é quanto à utilização de softwares no ambiente educacional, tais como o software GeoGebra, que tem sido investigado por alguns autores, dentre eles Araújo (2010) e Pereira (2012) e, o software Scratch, que aparece nas pesquisas de Curci (2017), Zoppo (2017) e Meireles (2017). 
O Scracth é o foco desta pesquisa, pois oferece uma programação intuitiva e de fácil aprendizado, sendo uma ferramenta gratuita que pode ser utilizada tanto on-line como off-line, por diferentes usuários. A utilização deste software nos diferentes níveis de ensino pode contribuir efetivamente com os processos de ensino e de aprendizagem.

Para a inserção do Scratch dentro das salas de aula, percebemos que se faz necessário estudar as suas possibilidades, com o intuito de conhecê-lo, para que ele seja utilizado como uma ferramenta que contribui com o desenvolvimento cognitivo do estudante. Por isso, nos propomos a apresentar a pesquisa desenvolvida em um curso de extensão ofertado para estudantes de cursos de graduação em diferentes licenciaturas, num centro universitário particular na cidade de Curitiba. Os objetivos do curso foram apresentar o Scratch, destacar suas potencialidades dentro do contexto escolar e levar os participantes a programar um Objeto de Aprendizagem (OA) a partir do software.

Os participantes puderam conhecer o software através de leitura de textos, manipulação do Scratch, produção de OA que eles programaram e análise das produções desenvolvidas pelos demais colegas. Iremos apresentar esta trajetória ao longo deste texto porém, inicialmente abordaremos um pouco sobre as tecnologias digitais na educação e sobre o software utilizado no curso.

\section{As tecnologias digitais no contexto escolar}

Os estudantes atualmente estão imersos em um mundo e em uma cultura digital, para Veen e Vrakking (2009, p. 47) “[...] esta geração de hoje é a primeira geração que ensina seus pais a usar um fórum, um telefone celular e a consultar sua conta bancária eletronicamente [...]". Com isso, percebemos que se faz necessária a utilização das tecnologias digitais (TD) dentro dos espaços escolares, pois, o estudante já está imerso em ambientes com estas tecnologias. Contudo, o uso das TD sem planejamento e objetivos pedagógicos, promove apenas uma alternância entre ferramentas, ou seja, do quadro para o computador, $\mathrm{e}$ os procedimentos $\mathrm{e}$ metodologias continuam descontextualizados.

Para Motta (2012, p. 79) "[...] a escola e os educadores devem compreender a realidade do mundo digital e utilizá-la de forma constante em sua práxis pedagógica, procurando traçar metas e estratégias que levem à compreensão dos estudantes". É possível levar os estudantes a uma postura diferente daquela de meros usuários das TD, contudo, os professores precisam estar preparados para direcioná-los nesse caminho. É necessário que o docente se capacite e que as diferentes instituições de ensino, além de se adaptarem à cultura tecnológica, também incentivem o uso dessas ferramentas dentro do ambiente escolar.

O uso frequente das TD pode efetivamente potencializar o espaço de aprendizado dentro das instituições escolares e, também podem modificar ou ressignificar as estruturas cognitivas dos estudantes. Lévy (2004, p. 32) pontua que "na medida em que a informatização avança, certas funções são eliminadas, novas habilidades aparecem, a ecologia cognitiva se transforma". Identificar as funções que são eliminadas no contexto educacional e substituí-las, ao ponto de possibilitar que os estudantes desenvolvam novas habilidades é uma alternativa, contudo, acreditamos que professores e escolas precisam primeiramente se posicionar a favor das TD na educação.

A relevância que o professor vai dar ao utilizar as tecnologias digitais diante dos conteúdos que quer explorar em sala de aula pode ser, efetivamente, o diferencial que proporcionará a aprendizagem destes conteúdos por parte dos estudantes. Para Kenski (2007, p. 19) é "[...] na ação do professor na sala de aula e no uso que ele faz dos suportes tecnológicos que se encontram à sua disposição[...]" é que são estabelecidas as relações entre os processos de ensino e aprendizagem por meio das TD. 
Acreditamos que preparar o docente para inserir as TD de forma a auxiliar os processos de ensino e de aprendizagem dentro do contexto de sala aula se torna importante. Levar os estudantes a interagir com possibilidades tecnológicas que sejam significativas, na qual eles mesmos possam modelar suas atividades de acordo com o interesse da turma, respeitando suas particularidades e regionalidades, tem se tornado uma premissa ao contexto educacional. Com isto, acreditamos que a capacitação para o uso das TD, durante a formação inicial, pode além de preparar o professor para a inserção pedagógica destes recursos em sala de aula, despertar o gosto pela utilização destes meios digitais, tão presentes no contexto social.

\section{O software de programação Scratch e Objetos de Aprendizagem}

Uma maneira de levar as tecnologias para o contexto escolar, de forma a colaborar com a socialização do conhecimento, é a utilização do software Scratch. Este software é gratuito e permite aos usuários programar OA, na forma de jogos digitais, de maneira intuitiva, não necessitando que usuário tenha conhecimento em programação. Salazar et al (2015) pontuam que o Scratch é uma linguagem visual de programação, desenvolvida para auxiliar na aprendizagem. Para os autores "O Scratch contém facilidades que permitem a qualquer pessoa sem conhecimentos prévios ou restrição de idade, criar [...]" (SALAZAR et. al., 2015, p. 1293).

Identificando estas potencialidades e diversidades do uso do Scratch, acreditamos ser viável que estudantes de cursos de graduação em diferentes licenciaturas o utilizem, pois eles podem ser levados a perceber as possibilidades de uso do software em diferentes contextos e espaços escolares. Salientamos que a definição de OA adotada nesta pesquisa é apresentada por Kalinke e Balbino (2016, p. 25), a qual pontua que um OA é "qualquer recurso virtual multimídia, que pode ser usado e reutilizado com o intuito de dar suporte à aprendizagem de um conteúdo específico, por meio de atividade interativa, apresentada na forma de animação ou simulação".

Percebemos que, além de levar os estudantes a programarem no Scratch, também é possível ao professor desenvolver seu próprio artefato digital, com atividades adaptadas a conteúdos que deseja explorar em sala de aula, fazendo com que sejam estabelecidas ligações entre o ato de ensinar e aprender. Zoppo (2017, p. 79) destaca que ao criar um OA, o professor "[...] utiliza o software como mais um material didático, mais uma estratégia de ensino, para contribuir no preparo de suas aulas".

Destarte, a produção de OA realizada pelo próprio professor pode beneficiar um aprofundamento dos conteúdos que estão sendo contemplados em sala de aula e ainda, pode indicar outros caminhos para o trabalho no contexto de sala de aula. Dito isto, percebemos a viabilidade de trabalhar com o Scratch com estudantes de diferentes licenciaturas, capacitando-os como futuros professores quanto ao uso desta tecnologia, e quanto às possibilidades pedagógicas que ela proporciona para a educação.

Nesta perspectiva, esta formação pode ocorrer de diferentes maneiras, seja na realização de cursos na formação inicial ou continuada, ou por meio de práticas de ensino ou extensão. Com isto, idealizamos o curso de formação sobre o software Scratch, o qual detalhamos na sequência do texto.

\section{Metodologia}

Inicialmente, cabe destacar que esta pesquisa tem caráter qualitativo pois, nos preocupamos mais com o caminho percorrido do que com os resultados obtidos durante a aplicação dos instrumentos metodológicos (GODOY, 1995). Destarte, o contexto para capacitação dos estudantes de cursos de licenciatura para o uso do software Scratch foi o nosso foco pois, assim como Imbernón (2011, apud Figueiredo e Goenwald, 2017, p. 96- 
97), acreditamos que a formação inicial de professores "é a primeira etapa para a aprendizagem profissional, em que devem ser fornecidos meios para a construção do conhecimento básico especializado".

O curso de extensão "Aprendendo a utilizar a ferramenta educacional Scratch", teve carga horária de 60 horas, sendo 20 horas presenciais e 40 horas a distância, foi ofertado para estudantes da graduação em diferentes licenciaturas, matriculados em cursos presenciais ou semipresenciais de um centro universitário particular de Curitiba. Foram realizados quatro encontros presenciais com duração de quatro horas cada e, foram desenvolvidas quatro atividades não presenciais. Buscamos levar os participantes a identificarem algumas possibilidades de inserção do software dentro do ambiente escolar antes de fazê-los programar um OA efetivamente.

Participaram deste estudo 10 estudantes, sendo um do curso de Licenciatura em Geografia, um do curso de Licenciatura em Letras, três do curso de Pedagogia e cinco do curso de Licenciatura em Matemática. Os participantes foram divididos em duplas, e para efeito de análise e inferências identificamos elas por A, B, C, D e E

Os encontros aconteceram uma vez por semana, na sala de informática da própria instituição, após os encontros foram realizadas atividades online, para que os estudantes fixassem os conteúdos e trabalhos nos momentos presenciais. Estas atividades foram desenvolvidas por meio de troca de mensagens eletrônicas (e-mail), entre os estudantes e os pesquisadores.

No encontro inicial verificamos o conhecimento prévio dos estudantes sobre o software, apresentamos algumas de suas ferramentas e proporcionamos a leitura e reflexão de alguns artigos que investigavam a criação de OA no Scratch. Como atividade online, as duplas produziram uma resenha sobre um dos textos propostos.

No segundo encontro, apresentamos o site oficial do Scratch no Brasil ${ }^{1}$ e o site Programaê! ${ }^{2}$. Após isto os participantes começaram a explorar o Scratch 2.0 que estava instalado nos computadores do laboratório de informática. Como o software apresenta duas versões disponíveis para download (Scratch 1.4 e 2.0), propomos, como atividade online, que eles instalassem as duas versões, em seus computadores, e fizessem um breve comparativo entre elas.

No terceiro encontro os participantes analisaram uma programação desenvolvida, previamente, pelos pesquisadores deste estudo. A partir dela, eles foram desafiados a programar um OA envolvendo conteúdos do Ensino Fundamental e que estivessem relacionados com sua futura formação. Foi proposto, como atividade online, a pesquisa e seleção de um conteúdo para elaboração de outro $\mathrm{OA}$, os estudantes também desenvolveram esta atividade em duplas e, puderam identificar as possibilidades de programação para o conteúdo escolhido.

Por fim, no quarto encontro, finalizamos o curso com a realização das apresentações das programações desenvolvidas na atividade online do encontro anterior. Os participantes tiveram a possibilidade de terminar seu objeto, apresentá-lo e contribuir com os projetos criados pelos colegas. $\mathrm{O}$ fechamento do curso ocorreu com o ajuste das programações dos OA, após os apontamentos realizados pelos colegas.

\section{Discussões dos dados da pesquisa}

A discussão, neste estudo, apresenta duas fases. Detalhamos a seguir os encontros presenciais e as atividades online desenvolvidas a partir de cada encontro, buscando caracterizar as contribuições do curso para formação dos participantes.

\footnotetext{
1 <http://www.scratchbrasil.net.br/>. Acesso em outubro de 2018.

${ }^{2}$ Site que oferece atividades que introduz o usuário aos conceitos básicos de programação, através de uma forma lúdica e intuitiva. Disponível em http://programae.org.br/
} 
No primeiro encontro presencial solicitamos que os participantes registrassem por escrito, individualmente, o que eles entendiam por Scratch. Este trabalho foi realizado com o intuito de identificar os conhecimentos de cada um em relação ao software. Observamos que alguns participantes demonstravam um conhecimento superficial enquanto outros não conheciam o programa.

Diante das colocações, foi possível verificar que o trabalho com o Scratch deveria acontecer de forma mais detalhada, ou seja, desde sua história até a situação de programação propriamente dita. Percebemos que seria necessário demonstrar todas as ferramentas do programa antes de propor aos participantes a construção de um OA.

Uma apresentação inicial sobre o software foi realizada, e nesta apresentação comentamos sobre a teoria construcionista ${ }^{3}$ de Papert, proporcionando a contextualização do trabalho a partir do desenvolvimento cognitivo que o Scratch possibilita. Ao final desta apresentação, os participantes foram separados em duplas e alguns artigos sobre o software foram entregues para leitura e aprofundamento. Os artigos utilizados foram escritos por Faria e Motta (2017); Andrade, Silva e Oliveira (2013); Neto (2013); e Aureliano e Tedesco (2012).

Cada dupla recebeu um artigo para ler e discutir, num tempo de aproximadamente 50 minutos, após este período, as duplas comentaram suas impressões sobre os textos lidos. Percebemos que esta atividade foi de grande valia, pois, os participantes identificaram algumas formas de utilizar o software em turmas da Educação Básica, bem como alguns processos de programação.

Foi proposto, como atividade online, que os participantes em duplas escolhessem um dos artigos propostos para leitura e, fizessem uma resenha sobre o mesmo. Essa resenha foi encaminhada para o e-mail dos pesquisadores. A dupla A pontuou que o artigo que escolheram para leitura os levou a perceber que o Scratch pode motivar estudantes no aprofundamento de seus estudos. As duplas B, C e E não enviaram a resenha e a dupla $\mathrm{D}$ colocou que a leitura do texto os levou a compreender um pouco mais sobre as possibilidades do software.

Percebemos que as duplas que realizaram as resenhas solicitadas, desenvolveram uma autonomia maior na realização das demais atividades propostas ao longo do curso. Cabe destacar que apesar do não envio da atividade pelas duplas B, C e E, os estudantes continuaram a participar do curso de forma ativa.

No segundo encontro presencial, a proposta inicial foi de explorar o site oficial do Scratch no Brasil e, também o site Programaê!, com o intuito de verificar as possibilidade existentes de OA construídos no Scratch. Ao visitar o site oficial do software os participantes puderam identificar diferentes atividades que contemplavam diferentes componentes curriculares, programadas a partir do software e ainda, puderam assistir a alguns tutoriais disponíveis no mesmo. Neste momento os estudantes se mostraram interessados em relação ao conteúdo do site, bem como com o processo de construção dos OA.

Após este primeiro contato com o site oficial do Scratch, apresentamos o site Programaê!, para que os participantes pudessem interagir e explorar outros OA. Neste segundo momento, os objetos foram programados utilizando personagens de jogos ou desenhos animados, e isto chamou a atenção dos estudantes que ficaram explorando o site de forma conjunta, o que contribuiu com uma ação colaborativa durante todo o curso.

Depois destas situações, os participantes passaram a explorar o próprio Scratch. Primeiro apresentamos as principais funções do software e algumas possibilidades de programação. Em seguida, os participantes passaram a realizar tentativas de programação

\footnotetext{
3 “[...] o Construcionismo estuda o desenvolvimento e o uso da tecnologia, em especial, do computador,
} na criação de ambientes educacionais" (MALTEMPI, 2012, p.287-288). 
de OA. Chamamos estas tentativas de programações de iniciais, pois não houve um planejamento para sua realização, elas foram acontecendo conforme os estudantes iam se familiarizando com o software. O intuito ao promover a interatividade dos estudantes com o Scratch foi de levá-los a compreender o funcionamento do software e, possibilitar a percepção de que é possível realizar programações intuitivas.

Como atividade online, sugerimos que instalassem em seus computadores pessoais as duas versões disponíveis do Scratch e elencassem semelhanças e diferenças entres as duas soluções. A principal diferença pontuada foi sobre a interface do usuário, ou seja, o que mais chamou a atenção dos estudantes, foi sobre o local no qual a programação é desenvolvida.

A partir disso as duplas passaram a escolher a versão que mais se identificaram para continuar desenvolvendo as atividades nos próximos encontros presenciais e, nas demais atividades online. As duplas A, B, C e E escolheram trabalhar com a versão $2.0 \mathrm{e}$ a dupla D optou pela versão 1.4.

Anterior à realização do terceiro encontro, os pesquisadores desenvolveram, na versão 1.4 do Scratch, a programação de um OA, no qual vogais do alfabeto "caiam" da parte superior da tela e o personagem principal deveria tocá-las de acordo com um parâmetro estabelecido e, para cada vogal correta, era gerado uma certa pontuação para o usuário (Figura 1). A programação para o personagem principal movimentar-se foi desenvolvida de tal maneira que a pessoa que estivesse explorando esta atividade digital deveria clicar nas teclas de setas direcionais do teclado.

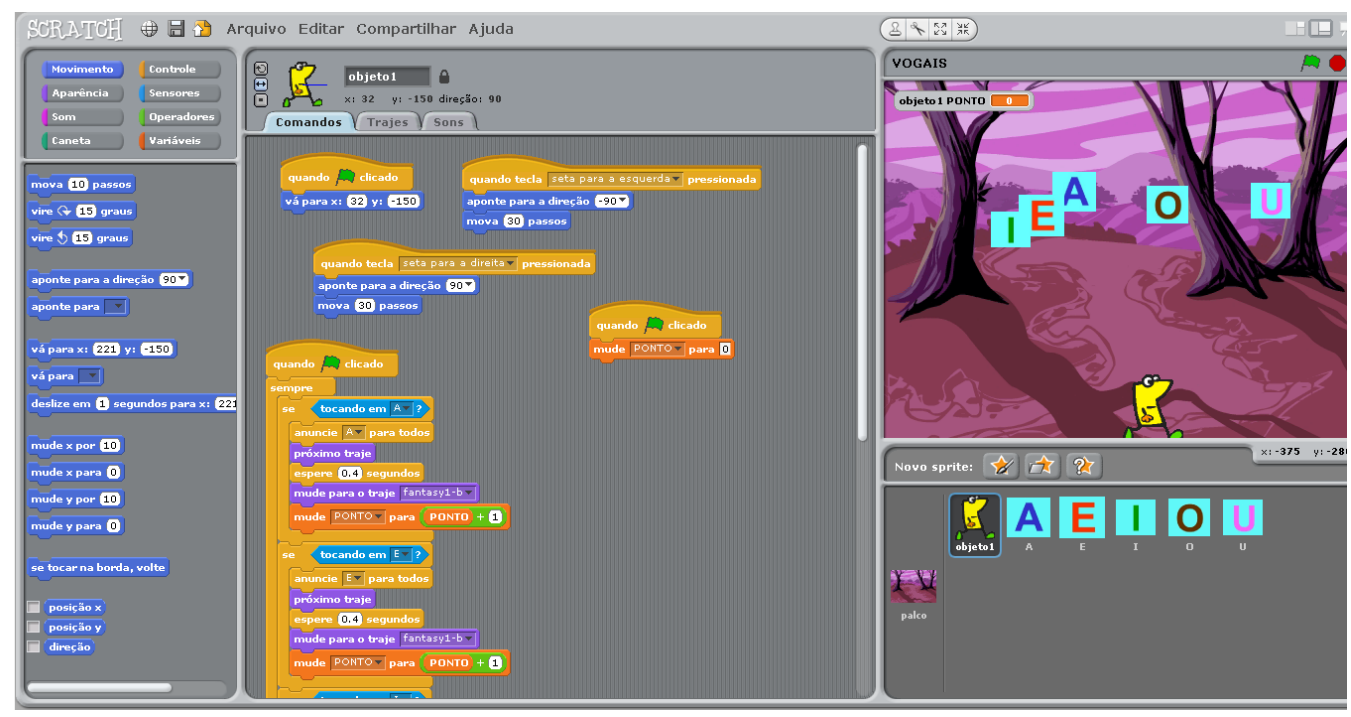

Figura 1: OA pré-programado.

Assim, no terceiro encontro, solicitamos às duplas, que desenvolvessem a programação de uma atividade semelhante a esta. A maior parte dos estudantes reproduziu parcialmente o modelo disponibilizado pelos pesquisadores. A dificuldade recorrente foi na realização da programação, pois, em alguns OA que estavam sendo desenvolvidos pelas duplas existiam vários personagens, o que exigia uma programação específica para cada um deles.

Percebemos que os participantes que precisaram de mais auxílio no desenvolvimento destas atividades foram aqueles com maior idade. Eles demonstravam medo de errar e "perder tempo", conforme eles mesmos apontavam. Ultrapassada a etapa de adaptação com a programação do Scratch, as atividades propostas neste encontro foram realizadas. Os estudantes demonstraram interesse em programar e expressaram contentamento por conseguirem desenvolver uma atividade de programação. 
Como atividade online, as duplas deveriam elaborar uma proposta de OA para o trabalho com turmas da Educação Básica. Como recomendação, solicitamos que o projeto fosse escolhido de acordo com a futura área de atuação da dupla. Eles deveriam também verificar possibilidades de programação para este OA, bem como colocar objetivos para a atividade, de tal maneira, que no próximo encontro eles já iniciassem com a programação propriamente dita.

No quarto encontro presencial percebemos que apenas três duplas realizaram a atividade proposta na semana anterior, e elas já iniciaram a programação de seus OA, conforme programado. As outras duplas tiveram de realizar as pesquisas, antes de iniciar o processo de programação. As duplas A e D demonstraram facilidade ao programar. A dupla $\mathrm{C}$, mesmo tendo realizado a atividade online, apresentou o mesmo nível de dificuldades que as duplas $\mathrm{B}$ e $\mathrm{E}$, que não realizaram a atividade online proposta, apresentaram.

Assim, no quarto encontro presencial, superada a etapa descrita anteriormente, todos os participantes passaram a desenvolver o programa intitulado de seu "projeto final". Foi dada a liberdade para os mesmos programarem em seus notebooks ou nos computadores da sala de informática do centro universitário.

Fizemos uma proposta de construção de um OA voltado para a Educação Básica. Esta construção foi desenvolvida de maneira mais autônoma pelas duplas, em relação as atividades propostas anteriormente. Enquanto pesquisadores, fomos auxiliando-os sempre que solicitavam, mas buscamos em cada intervenção questioná-los e levá-los a refletir sobre o processo que estavam desenvolvendo, sem indicar respostas ou possíveis caminhos para a construção do OA.

Para programar, cada dupla utilizou uma estratégia diferente. Algumas foram programando diretamente no Scratch. Uma das duplas, antes de iniciar a programação, assistiu alguns tutoriais disponíveis na internet. Outras duplas conversavam primeiramente, trocando ideias e pontuando como iriam desenvolver a programação sugerida. E ainda, alguns participantes visitaram novamente o site do Scratch Brasil para, posteriormente, iniciar a programação.

Após a programação realizada neste encontro, os estudantes apresentaram seus OA à turma. Cada dupla foi mostrando os objetivos dos OA, para qual nível de ensino ele foi desenvolvido e como se deu a programação. Neste momento, os demais colegas puderam emitir opiniões, indicar inconsistências, fazer sugestões de novas maneiras de programar bem como de utilização do OA. Destacaremos a seguir três projetos desenvolvidos pelos participantes do curso. Os demais projetos, apesar de terem sido desenvolvidos nos encontros presenciais não foram entregues aos pesquisadores, não sendo possível realizar considerações nesta investigação.

A dupla A desenvolveu um OA para ser utilizado em turmas do Ensino Fundamental I, com o intuito de trabalhar números múltiplos. A programação exigia que o estudante encontrasse os múltiplos de 2, conforme é possível observar na Figura 2. O código destes participantes foi desenvolvido na versão 2.0, eles mostraram conhecer as ferramentas do Scratch. A dupla, não apresentou dificuldades em programar, solicitando auxílio, poucas vezes, e buscaram trabalhar com um layout atrativo aos usuários. 


CINTED-UFRGS Novas Tecnologias na Educação

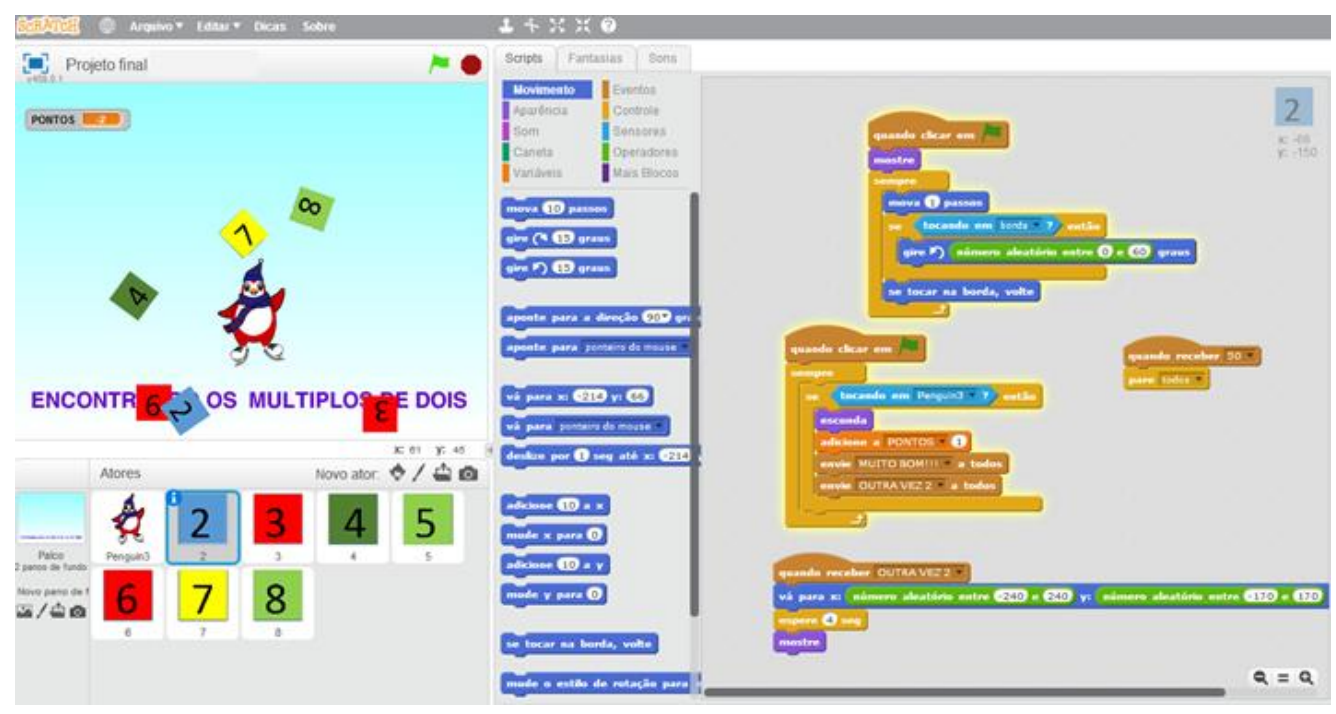

Figura 2: OA desenvolvido pela dupla $\mathrm{A}$.

A dupla $\mathrm{C}$ programou um OA que envolvia o reconhecimento das vogais. Segundo os estudantes, esse objeto foi escolhido porque ele poderia ser aplicado em turmas do Ensino Fundamental I e em turmas de Educação Infantil. Como um dos integrantes desta dupla já atua como docente em uma instituição de Educação Infantil, percebeu-se que a programação desenvolvida poderia contribuir em seu ambiente profissional. Esta programação também foi realizada na versão 2.0 (ver Figura 3). Esta dupla apresentou muitas dificuldades ao programar, solicitando auxílio dos pesquisadores e demais colegas em diferentes momentos.

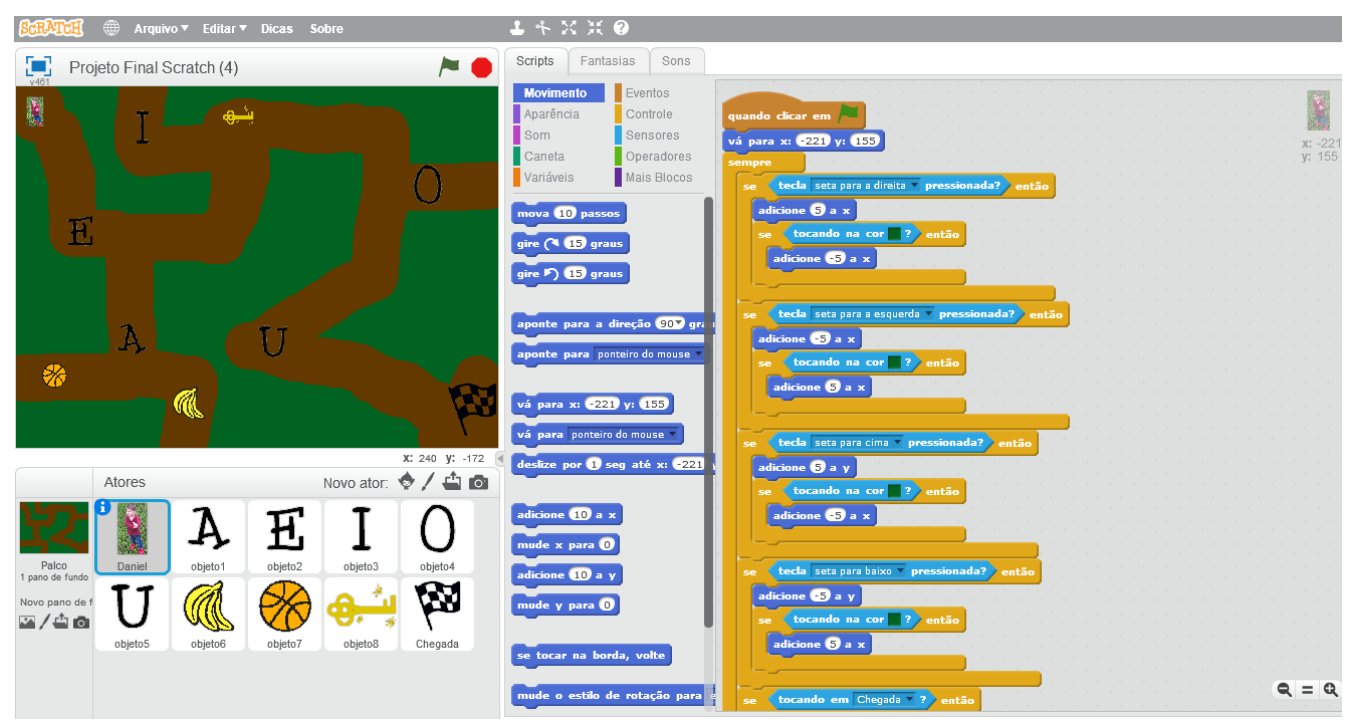

Figura 3: OA desenvolvido pela dupla $C$.

Por fim, a dupla D desenvolveu um OA que contemplava o conteúdo de equação do $1^{\circ}$ grau (Figura 4). Esta dupla se identificou com a versão 1.4 do software e, programou o OA no notebook pessoal de um dos integrantes da dupla. Eles mostraram poucas dificuldades para realizar a programação e não demonstraram muito interesse em apresentar um layout mais elaborado. Utilizaram o personagem principal do software e apenas um fundo de tela já disponível no próprio programa. 


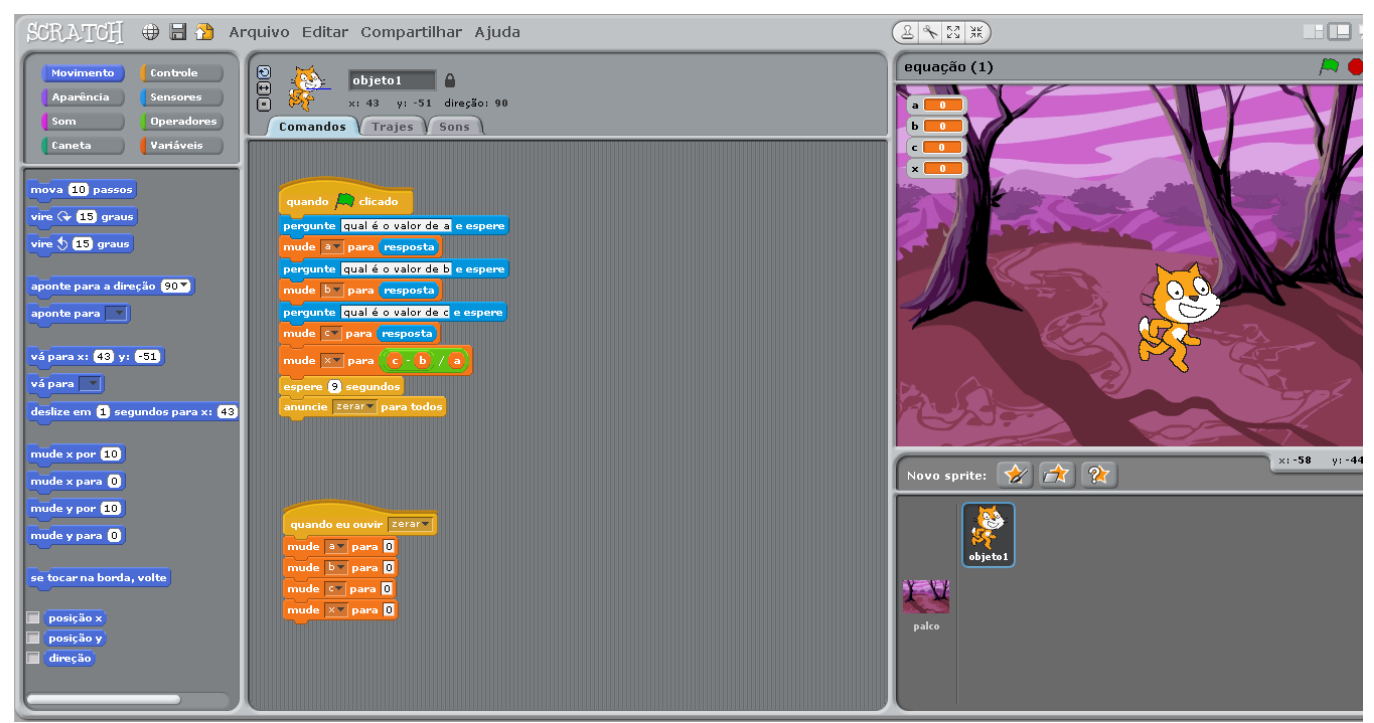

Figura 4: OA desenvolvido pela dupla $D$.

Apesar dos projetos das duplas B e E, não terem sido entregues, durante a construção observamos que a dupla $B$ não apresentava grandes dificuldades ao programar, enquanto a dupla E precisou de auxílio constante, como os integrantes da dupla C.

Antes de finalizarmos este encontro, sugerimos, como atividade online, que as duplas avaliassem seus projetos, bem como as alterações sugeridas pelos demais colegas e verificassem se elas realmente eram necessárias. Depois dessas adequações, as duplas deveriam entregar os projetos finais, conforme já citamos anteriormente.

Ao final deste encontro solicitamos aos estudantes que comentassem sobre o Scratch e sobre as possibilidades de seu uso em turmas da Educação Básica. Durante esta conversa, um estudante citou que "O Scratch é bom, porém a precariedade das escolas públicas pode impossibilitar o trabalho com o mesmo". A partir desta fala, alguns participantes passaram a comentar sobre as diferentes maneiras de trazer esta ferramenta para o contexto escolar: utilizando os laboratórios de informática das instituições escolares; fazendo uso de notebooks disponíveis em algumas escolas públicas e através da lousa digital. Os participantes pontuaram que poderiam ser propostas nas salas de aula em seus cursos de Licenciatura, atividades com o software, para que eles pudessem identificar mais possibilidades de uso do Scratch. Ainda nesta conversa final, os participantes demonstraram a intenção de levar este recurso para a sala de aula quando se tornarem professores atuantes no mercado de trabalho

O Scratch era uma ferramenta nova para a maior parte dos participantes do curso, eles aprenderam a utilizá-la e perceberam a possibilidade de desenvolver um OA de acordo com suas necessidades e interesses. Percebemos que o curso possibilitou aos participantes identificarem que é possível utilizar diferentes TD nas salas de aula, de forma a beneficiar os processos de ensino e de aprendizagem.

\section{Considerações Finais}

Por meio desta pesquisa foi possível perceber que existe uma demanda, por parte de estudantes de graduação em licenciaturas, em conhecer as TD disponíveis para o trabalho em sala de aula. Dito isto, acreditamos que apesar do Scratch ser uma ferramenta bastante divulgada nos meios de comunicação digital, grande parte dos participantes tiveram o primeiro contato com a ferramenta no próprio curso. Consideramos que os objetivos propostos inicialmente neste estudo, de apresentar esta ferramenta e suas potencialidades aos participantes do curso e de capacitar os mesmos a programar OA, 
foram atingidos. E, conforme citado por Zoppo (2017), tivemos a oportunidade de apresentar o Scratch como uma ferramenta que pode contribuir com o professor no preparo das aulas.

O fato é que participantes tiveram o primeiro contato com o software Scratch no curso e demonstram inicialmente dificuldades em explorá-lo, bem como de elaborar diferentes OA. Isto nos fez refletir sobre o quanto temos efetivamente preparado nossos acadêmicos das licenciaturas para o mercado de trabalho, para atuarem efetivamente em sala de aula desenvolvendo seus próprios materiais didáticos, sejam eles digitais ou não. Certamente, a prática profissional também os auxiliará no decorrer de suas carreiras, como cita Motta (2012), as instituições escolares e os professores devem entender a realidade do mundo digital e utilizá-la com frequência. Neste viés, devemos levar em consideração que estes acadêmicos, futuros professores, irão trabalhar diretamente com uma geração que já está inserida no contexto das TD.

Além de programar utilizando o Scratch, realizamos leituras de textos que abordavam trabalhos desenvolvidos com o software. Verificamos nessas leituras, que os estudantes conseguiram assimilar alguns pontos positivos em utilizar o Scratch na sala de aula e puderam ter acesso a uma literatura diferente daquelas com as quais já estão trabalhando ao longo de seus cursos de licenciaturas.

Aprender a utilizar as diferentes funções do Scratch, bem como ter a possibilidade de conhecer duas versões diferentes do software levou os estudantes a focarem nas possibilidades de utilizarem o programa no contexto da Educação Básica. Com isto, os participantes puderam fazer reflexões sobre a prática do professor, verificar as possibilidades de uso de uma TD em sala de aula e, perceber que é possível programar um OA a partir das demandas apresentadas pelo seu planejamento e necessidades dos estudantes.

Apesar de duas duplas não terem entregado o projeto final, a construção pode ser acompanhada pelos pesquisadores, no quarto encontro presencial e, alguns participantes pensaram em toda a estrutura do OA que desenvolveram, buscando fazer um layout atrativo ao usuário, bem como uma programação mais elaborada.

Com os resultados apresentados, destacamos que é possível capacitar professores em formação para a utilização do software Scratch, seja em qualquer componente curricular ou nível de ensino. Por fim, acreditamos que cursos de licenciaturas precisam promover o uso das TD de forma significativa, de maneira que esta utilização faça sentido aos futuros profissionais da educação. Ousamos sugerir que novas práticas de extensão, similares a apresentada ao longo deste texto, sejam ofertadas e, propomos que os trabalhos desenvolvidos pelos participantes dos cursos sejam aplicados no contexto da educação básica, de maneira que seja possível verificar se os OA desenvolvidos atingiram o objetivo idealizado durante o processo de construção.

\section{Referências}

ANDRADE, M.; SILVA, C.; OLIVEIRA, T. Desenvolvendo games e aprendendo matemática utilizando o Scratch. Simpósio Brasileiro de Jogos e Entretenimento Digital. São Paulo, p. 260-263, 2013.

AURELIANO, V. C. O.; TEDESCO, P. C. A. R. Avaliando o uso do Scratch como abordagem alternativa para o processo de ensino-aprendizagem de programação. In: $\mathbf{X X}$ Workshop sobre Educação em Computação. 2012.

BORBA, M. C.; LACERDA, H. D. G. Políticas Públicas e Tecnologias Digitais: um celular por estudante. Educação Matemática Pesquisa, v. 17, n.3, 2015.

CURCI, A. P. F.; MOTTA, M. S. Aprendendo Matemática ao se Programar no

Scratch. Revista Educação \& Tecnologia, n. 16, 2017. 
DEROSSI, B. Objetos de aprendizagem e lousa digital no trabalho com Álgebra: as estratégias dos estudantes na utilização dessas ferramentas. 2015. 136 f. Dissertação (Mestrado em Educação em Ciências e Matemática). Universidade Federal do Paraná, Curitiba, 2015.

FIGUEIREDO, F. F.; GROENWALD, C. L. O. Produzindo Problemas Abertos Utilizando Tecnologias Digitais no Processo de Formação Inicial de Professores de Matemática. Revista de Ensino de Ciências e Matemática, v. 8, n. 2, p. 95-114, 2017. GODOY, A. S. Introdução à pesquisa qualitativa e suas possibilidades. Revista de administração de empresas, v. 35, n.2, p. 57-63, 1995.

KALINKE, M. A.; MOCROSKY, L. F. Educação Matemática: pesquisas e posibilidades. Curitiba: ed. UTFPR, 2015.

KALINKE, M. A.; BALBINO, R. O. Lousas Digitais e Objetos de Aprendizagem. In: KALINKE, M. A.; MOCROSKY, L. F. (Org.). A lousa digital e outras tecnologías na Educação Matemática. Curitiba: CRV, 2016. p. 13-31.

KENSKI, V. M. Educação e Tecnologias o novo ritmo da informação. Campinas SP: Papirus, 2007.

LÉVY, P. As tecnologias da Inteligência - O futuro do pensamento na era da informática. São Paulo. Editora 34. Tradução de Carlos Irineu da Costa. 2004.

MALTEMPI, M. V. Construcionismo: pano de fundo para pesquisas em informática aplicada à Educação Matemática. In: BICUDO, Maria Aparecida Vigiani; BORBA, M. C. (Org). Educação Matemática: pesquisa em movimento, $3^{a}$ ed. São Paulo: Cortez, 2012.

MEIRELES, T. F. Desenvolvimento de um objeto de aprendizagem de Matemática usando o Scratch: da elaboração à construção. Anais do XX EBRAPEM - Encontro Brasileiro de Estudantes de Pós-Graduação em Educação Matemática. Curitiba, 2016.

MOTTA, M. S. O Estágio Supervisionado na Formação Inicial do Professor de Matemática no Contexto das Tecnologias Educacionais. 2012. $343 \mathrm{f}$. Tese (Doutorado em Ensino de Ciências e Matemática). Universidade Cruzeiro do Sul. São Paulo. 2012.

, M. S. Formação inicial do professor de matemática no contexto das tecnologías digitais. Revista Contexto \& Educação, v. 32, n. 102, p. 170-204, 2017. NETO, V. S. M. A utilização da ferramenta Scratch como auxílio na aprendizagem de lógica de programação. In: Anais dos Workshops do Congresso Brasileiro de Informática na Educação. 2013.

RIBEIRO, M. S. N. A lousa digital no fundamental I: formas de utilização no ensino da Matemática. 2015. 110 f. Dissertação (Mestrado em Educação em Ciências e em Matemática). Universidade Federal do Paraná. Curitiba. 2015.

SALAZAR, R.; ODAKURA, V.; BARVINSKI, C. Scratch no ensino superior: motivação. In: Brazilian Symposium on Computers in Education (Simpósio Brasileiro de Informática na Educação-SBIE). 2015. p. 1293.

VEEN, W.; VRAKKING, B. Homo Zappiens: educando na era digital. Porto Alegre: Artmed, 2009.

ZOPPO, B. M. A contribuição do scratch como possibilidade de material didático digital de matemática no ensino fundamental. 2017. 135 f. Dissertação (Mestrado em Educação em Ciências e em Matemática). Universidade Federal do Paraná. Curitiba. 2017. 